\title{
Impaired myocardial metabolic reserve and substrate selection flexibility during stress in patients with idiopathic dilated cardiomyopathy
}

Danilo Neglia, Alberto De Caterina, Paolo Marraccini, Andrea Natali, Marco

Ciardetti, Cecilia Vecoli, Amalia Gastaldelli, Demetrio Ciociaro, Paola Pellegrini, Roberto Testa, Luca Menichetti, Antonio L'Abbate, William C. Stanley and Fabio A. Recchia

Am J Physiol Heart Circ Physiol 293:H3270-H3278, 2007. First published 5 October 2007;

doi:10.1152/ajpheart.00887.2007

You might find this additional info useful...

Supplemental material for this article can be found at:

http://ajpheart.physiology.org/content/suppl/2007/10/17/00887.2007.DC1.html

This article cites 38 articles, 28 of which can be accessed free at:

http://ajpheart.physiology.org/content/293/6/H3270.full.html\#ref-list-1

This article has been cited by 15 other HighWire hosted articles, the first 5 are:

Unfavourable consequences of chronic cardiac HIF-1 $\alpha$ stabilization

Marion Hölscher, Katrin Schäfer, Sabine Krull, Katja Farhat, Amke Hesse, Monique Silter, Yun

Lin, Bernd J. Pichler, Patricia Thistlethwaite, Ali El-Armouche, Lars. S. Maier, Dörthe M.

Katschinski and Anke Zieseniss

Cardiovasc Res, April 1, 2012; 94 (1): 77-86.

[Abstract] [Full Text] [PDF]

Unfavourable consequences of chronic cardiac HIF-1 $\alpha$ stabilization

Marion Hölscher, Katrin Schäfer, Sabine Krull, Katja Farhat, Amke Hesse, Monique Silter, Yun

Lin, Bernd J. Pichler, Patricia Thistlethwaite, Ali El-Armouche, Lars. S. Maier, Dörthe M.

Katschinski and Anke Zieseniss

Cardiovasc Res, January 18, 2012; .

[Abstract] [Full Text] [PDF]

Inhibition of c-Jun-N-terminal Kinase Increases Cardiac Peroxisome

Proliferator-activated Receptor $\alpha$ Expression and Fatty Acid Oxidation and Prevents

Lipopolysaccharide-induced Heart Dysfunction

Konstantinos Drosatos, Zoi Drosatos-Tampakaki, Raffay Khan, Shunichi Homma, P. Christian

Schulze, Vassilis I. Zannis and Ira J. Goldberg

J. Biol. Chem., October 21, 2011; 286 (42): 36331-36339.

[Abstract] [Full Text] [PDF]

Modulating fatty acid oxidation in heart failure

Vincenzo Lionetti, William C. Stanley and Fabio A. Recchia

Cardiovasc Res, May 1, 2011; 90 (2): 202-209.

[Abstract] [Full Text] [PDF]

Modulating fatty acid oxidation in heart failure

Vincenzo Lionetti, William C. Stanley and Fabio A. Recchia

Cardiovasc Res, February 2, 2011; .

[Abstract] [Full Text] [PDF]

Updated information and services including high resolution figures, can be found at: http://ajpheart.physiology.org/content/293/6/H3270.full.html

Additional material and information about AJP - Heart and Circulatory Physiology can be found at: http://www.the-aps.org/publications/ajpheart

AJP - Heart and Circulatory Physiology publishes original investigations on the physiology of the heart, blood vessels, and lymphatics, including experimental and theoretical studies of cardiovascular function at all levels of organization ranging from the intact animal to the cellular, subcellular, and molecular levels. It is published 12 times a year (monthly) by the American

Physiological Society, 9650 Rockville Pike, Bethesda MD 20814-3991. Copyright @ 2007 by the American Physiological Society. ISSN: 0363-6135, ESSN: 1522-1539. Visit our website at http://www.the-aps.org/. 
This information is current as of April 18, 2012.

AJP - Heart and Circulatory Physiology publishes original investigations on the physiology of the heart, blood vessels, and lymphatics, including experimental and theoretical studies of cardiovascular function at all levels of organization ranging from the intact animal to the cellular, subcellular, and molecular levels. It is published 12 times a year (monthly) by the American

Physiological Society, 9650 Rockville Pike, Bethesda MD 20814-3991. Copyright @ 2007 by the American Physiological Society. ISSN: 0363-6135, ESSN: 1522-1539. Visit our website at http://www.the-aps.org/. 


\title{
TRANSLATIONAL PHYSIOLOGY
}

\section{Impaired myocardial metabolic reserve and substrate selection flexibility during stress in patients with idiopathic dilated cardiomyopathy}

\author{
Danilo Neglia, ${ }^{1}$ Alberto De Caterina, ${ }^{3}$ Paolo Marraccini, ${ }^{1}$ Andrea Natali, ${ }^{2}$ Marco Ciardetti, ${ }^{1}$ \\ Cecilia Vecoli, ${ }^{3}$ Amalia Gastaldelli, ${ }^{1}$ Demetrio Ciociaro, ${ }^{1}$ Paola Pellegrini, ${ }^{1}$ Roberto Testa, ${ }^{1}$ \\ Luca Menichetti, ${ }^{1}$ Antonio L'Abbate, ${ }^{1,3}$ William C. Stanley, ${ }^{3}$ and Fabio A. Recchia ${ }^{3,4}$ \\ ${ }^{1}$ Institute of Clinical Physiology, National Council for Research; ${ }^{2}$ Department of Medicine, University of Pisa; ${ }^{3}$ Scuola \\ Superiore Sant'Anna, Pisa, Italy; and ${ }^{4}$ Department of Physiology, New York Medical College, Valhalla, New York
}

Submitted 28 July 2007; accepted in final form 1 October 2007

\begin{abstract}
Neglia D, De Caterina A, Marraccini P, Natali A, Ciardetti M, Vecoli C, Gastaldelli A, Ciociaro D, Pellegrini P, Testa R, Menichetti L, L'Abbate A, Stanley WC, Recchia FA. Impaired myocardial metabolic reserve and substrate selection flexibility during stress in patients with idiopathic dilated cardiomyopathy. Am J Physiol Heart Circ Physiol 293: H3270-H3278, 2007. First published October 5, 2007; doi:10.1152/ajpheart.00887.2007._Under resting conditions, the failing heart shifts fuel use toward greater glucose and lower free fatty acid (FFA) oxidation. We hypothesized that chronic metabolic abnormalities in patients with dilated cardiomyopathy (DCM) are associated with the absence of the normal increase in myocardial glucose uptake and maintenance of cardiac mechanical efficiency in response to pacing stress. In $10 \mathrm{DCM}$ patients and 6 control subjects, we measured coronary flow by intravascular ultrasonometry and sampled arterial and coronary sinus blood. Myocardial metabolism was determined at baseline, during atrial pacing at 130 beats/min, and at $15 \mathrm{~min}$ of recovery by infusion of $\left[{ }^{3} \mathrm{H}\right]$ oleate and $\left[{ }^{13} \mathrm{C}\right]$ lactate and measurement of transmyocardial arteriovenous differences of oxygen and metabolites. At baseline, DCM patients showed depressed coronary flow, reduced uptake and oxidation of FFA, and preferential utilization of carbohydrates. During pacing, glucose uptake increased by $106 \%$ in control subjects but did not change from baseline in DCM patients. Lactate release increased by $122 \%$ in DCM patients but not in control subjects. Cardiac mechanical efficiency in DCM patients was not different compared with control subjects at baseline but was 34\% lower during stress. Fatty acid uptake and oxidation did not change with pacing in either group. Our results show that in DCM there is preferential utilization of carbohydrates, which is associated with reduced flow and oxygen consumption at rest and an impaired ability to increase glucose uptake during stress. These metabolic abnormalities might contribute to progressive cardiac deterioration and represent a target for therapeutic strategies aimed at modulating cardiac substrate utilization.
\end{abstract}

microcirculation

FATTY ACIDS provide $60-90 \%$ of the energy necessary to sustain contractile function in the resting fasting state, with the remainder coming from glucose and lactate oxidation. During acute cardiac stress, such as pacing or exercise, the healthy human heart rapidly increases glucose and lactate uptake, with a relative decline in free fatty acid (FFA) uptake $(1,3,4,9)$. Clinical and animal studies have suggested that this response is

Address for reprint requests and other correspondence: D. Neglia, Institute of Clinical Physiology, National Council for Research, Pisa 56124, Italy (e-mail: dneglia@ifc.cnr.it). advantageous: it increases myocardial metabolic efficiency, since carbohydrates are a more efficient substrate than lipids, generating more contractile power for any given rate of myocardial oxygen consumption $\left(\mathrm{MV}_{2}\right)(20,29,31)$.

Dilated cardiomyopathy (DCM) is often characterized by reduced FFA uptake and oxidation and accelerated glycolysis and glucose oxidation under resting conditions $(7,21$, 31). This metabolic shift may act to optimize the limited oxidative capacity of cardiomyopathic hearts resulting from impairment of mitochondrial function (28) and/or ATP transfer from mitochondria to the contractile apparatus (30) or reduced myocardial perfusion and flow reserve due to coronary microvascular dysfunction $(16,17)$. Little is known about myocardial metabolism in DCM patient under conditions of increased workload. Factors that differentiate DCM from healthy conditions (altered metabolic phenotype, limited oxidative capabilities, reduced flow availability, etc.) might limit the ability of the dysfunctional myocardium to adapt to acute stress. The myocardial metabolic and flow response to acute atrial pacing stress has been extensively investigated in patients with syndrome $\mathrm{X}(1,3)$ and coronary artery disease $(23,24,39)$ but not in DCM patients. This information is clinically relevant, since metabolic modulators, such as agents that partially inhibit myocardial FFA oxidation, improve symptoms of stress-induced ischemia in angina patients (32) and ventricular function in patients with ischemic cardiomyopathy $(2,13,31,37)$, but the rationale for their potential use in heart failure and DCM is still under debate.

The purpose of the present investigation was to assess the relationships among cardiac substrate metabolism, ventricular dysfunction, and coronary blood flow (CBF) at rest and in response to acute pacing stress in DCM patients and in a control group of patients with normal coronary arteries and left ventricular (LV) mass and volume. We hypothesized that the chronic metabolic abnormalities in DCM observed at rest are associated with the absence of the normal response to pacing stress, namely, an increase in myocardial glucose uptake and maintenance of cardiac mechanical efficiency. Coronary hemodynamics and myocardial substrate metabolism were measured directly by cardiac catheterization and transmyocardial

The costs of publication of this article were defrayed in part by the payment of page charges. The article must therefore be hereby marked "advertisement" in accordance with 18 U.S.C. Section 1734 solely to indicate this fact. 
blood sampling using an infusion of $\left[{ }^{3} \mathrm{H}\right]$ oleate and $\left[{ }^{13} \mathrm{C}\right] \mathrm{lac}-$ tate tracers.

\section{MATERIALS AND METHODS}

\section{Study Population}

From October 2003 to May 2006, we enrolled 10 consecutive patients with DCM and 6 patients with normal LV function (controls), which were selected among the 329 patients admitted to the cardiology unit of the Institute of Clinical Physiology in Pisa, Italy, and showed normal coronary arteries with angiography. DCM patients were selected according to the following inclusion criteria: age between 20 and $80 \mathrm{yr}$, LV ejection fraction (EF) $<40 \%$, LV enddiastolic diameter (LVEDD) $>56 \mathrm{~mm}$, and angiographically normal coronary arteries $(<50 \%$ coronary diameter stenosis). Exclusion criteria were as follows: New York Heart Association (NYHA) class IV, previous myocardial infarction, valvular heart disease, actual systemic arterial hypertension, myocardial active inflammatory/infective diseases (such as myocarditis or pericarditis), current cigarette smoking, diabetes, or the presence of other systemic illnesses (such as neoplasia, renal, hepatic, or respiratory failure or atrial fibrillation). Control patients underwent coronary angiography for history of angina-like chest pain and/or previous stress tests suspicious for myocardial ischemia. Inclusion criteria for control patients were as follows: age between 20 and $80 \mathrm{yr}, \mathrm{LV}$ EF $>50 \%$, LVEDD $<56 \mathrm{~mm}$, angiographically normal coronary arteries $(<50 \%$ coronary diameter reduction), and the absence of other cardiovascular or systemic diseases.

Both groups of patients underwent routine blood tests, ECG, chest $\mathrm{X}$-ray, and resting two-dimensional echocardiogram. LV function, dimension, and mass were evaluated from two-dimensional echocardiogram data according to standardized protocols (12). Eight DCM patients were also submitted, within 30 days after the catheterization procedure, to PET with $\left[{ }^{13} \mathrm{~N}\right]$ ammonia to measure the specific blood flow per gram of myocardial tissue $\left(\mathrm{ml} \cdot \mathrm{min}^{-1} \cdot \mathrm{g}^{-1}\right)$ at rest. Specific flow was computed according to standardized protocols (17) in the left anterior descending coronary artery (LAD) myocardial territory (5).

The study was approved by the local ethical committee and conformed to the Declaration of Helsinki on human research, and written informed consent was obtained on the day before cardiac catheterization after complete explanation of the protocol and potential risks. All coronary-active drugs, including nitrates, $\mathrm{Ca}^{2+}$ antagonists, $\beta$-blockers, angiotensin-converting enzyme inhibitors, or statins, were suspended at least $24 \mathrm{~h}$ before catheterization.

\section{Cardiac Catheterization}

In the morning, after an overnight fast, all patients were submitted to routine coronary angiography and definitively enrolled after excluding the presence of significant coronary stenosis.

Cardiac catheterization was performed to measure coronary perfusion pressure, flow velocity, and cross-sectional area in the proximal third of the LAD and transmyocardial arteriovenous gradients across the LAD myocardial territory of labeled $\left(\left[\mathrm{L}-3-{ }^{13} \mathrm{C}\right]\right.$ lactate and $\left[9,10-{ }^{3} \mathrm{H}\right]$ oleate) and nonlabeled substrates (FFA, glucose, and lactate). At the completion of diagnostic catheterization, an intravenous bolus of $110 \mathrm{mg}\left[\mathrm{L}-3-{ }^{13} \mathrm{C}\right]$ lactate was administered, followed by an intravenous continuous infusion of $\left[9,10-{ }^{3} \mathrm{H}\right]$ oleate at $84 \mu \mathrm{Ci} / \mathrm{h}$ and $\left[\mathrm{L}-3-{ }^{13} \mathrm{C}\right]$ lactate at $130 \mathrm{mg} / \mathrm{h}$, allowing a 30 -min equilibration period. The $\left[{ }^{13} \mathrm{C}\right]$ lactate tracer was used to measure the simultaneous lactate uptake and efflux from the myocardium $(8,9,39)$, and the $\left[{ }^{3} \mathrm{H}\right]$ oleate tracer was used to measure FFA oxidation from the myocardial production of ${ }^{3} \mathrm{H}_{2} \mathrm{O}$ (21). A 6-Fr guiding catheter was placed in the left main coronary ostium through a 7-Fr femoral artery introducer. An intracoronary heparin bolus $(100 \mathrm{U} / \mathrm{Kg}$ ) was given, and a 0.014-in. Doppler flow wire (FloWire, Volcano) was advanced into the LAD. A 2.9-Fr, 10-MHz intravascular ultrasound (IVUS) catheter (Eagle Eye Gold, Volcano) was passed over the flow wire and positioned in the
LAD coronary artery immediately distal to the first septal perforating branch. The Doppler flow wire was positioned $2 \mathrm{~cm}$ distal to the tip of the IVUS catheter to avoid artifacts caused by the catheter wake. The positions of the IVUS catheter and flow wire were documented by angiography and maintained throughout the study by fluoroscopic control. After LAD instrumentation, a 5-Fr catheter was advanced into the coronary sinus, up to the great cardiac vein, to withdraw venous blood from the LAD territory, and a unipolar pacing catheter was then positioned into the right atrium. Due to the complexity of the instrumentation, five additional patients, fulfilling the inclusion criteria but in whom the catheterization procedures could not be completed, were excluded from the study.

After calibration, phasic and mean coronary perfusion pressure (from the guiding catheter) and coronary flow velocity signals were continuously recorded on paper and acquired, together with ECG (leads DI-DII-DIII), on a personal computer equipped with dedicated software. IVUS images were obtained for $\geq 30 \mathrm{~s}$ at each step of the protocol, with temporal synchronization with flow velocity signals, and recorded for off-line analysis.

At each step of the protocol, arterial and venous blood samples were withdrawn simultaneously, over $30 \mathrm{~s}$, from the femoral artery introducer and great cardiac vein and immediately processed for gas analysis and measurements of metabolite concentrations.

\section{Study Protocol}

The study protocol consisted of four steps. After the instrumentation was completed ( $\sim 30 \mathrm{~min})$, continuous monitoring of coronary hemodynamic signals was started and the baseline arteriovenous sampling was performed ("Baseline"). Heart rate was increased by atrial pacing to 110 beats/min for $3 \mathrm{~min}$ and to 130 beats/min for 3 additional min, and arteriovenous sampling was repeated ("Pacing"). Pacing was then stopped, and, 15 min later, a third pair of arteriovenous samples was withdrawn ("Recovery"). After an additional 15 min, when all hemodynamic parameters had returned to baseline, an intravenous adenosine infusion was given for 3 min unless it was not clinically tolerated or significant bradycardia (HR $<50$ beats/min) or hypotension (systolic pressure $<90 \mathrm{mmHg}$ ) occurred. Coronary parameters were acquired at the end of the third minute of adenosine administration, or just before suspension, and were used to estimate coronary flow reserve.

\section{Data Analysis}

Coronary flow. Coronary flow was calculated offline by multiplying Doppler-derived mean flow velocity by coronary lumen crosssectional area as measured by IVUS as described in the Data Supplement. ${ }^{1}$

Coronary flow reserve was computed as adenosine/resting CBF. An estimate of myocardial mechanical efficiency was obtained from the rate-pressure product (RPP) and $\mathrm{MVO}_{2}$ measured at each step as follows (see also the Data Supplement):

$$
(\mathrm{RPP} / \mathrm{LV} \text { mass }) /\left[\mathrm{MV}_{2} /(0.54 \times \mathrm{LV} \text { mass })\right]=(\mathrm{RPP} \times 0.54) / \mathrm{MV}_{\mathrm{O}_{2}} .
$$

Metabolites. Blood samples from the femoral artery and coronary sinus were withdrawn slowly to avoid hemolysis and potential contamination with right atrial blood. The first $5 \mathrm{ml}$ from the coronary sinus catheter were discarded to avoid contamination from either saline or blood present in the catheter. Oxygen consumption and metabolite uptake and oxidation were measured as previously described $(9,10,26)$ (see Data Supplement). The percent $\mathrm{MV}_{2}$ due to FFA or lactate oxidation was calculated as previously described (26). For lactate, it was assumed that $100 \%$ of the $\left[{ }^{13} \mathrm{C}\right]$ lactate taken up by the heart was oxidized to $\mathrm{CO}_{2}(9)$.

\footnotetext{
${ }^{1}$ Supplemental material for this article is available online at the American Journal of Physiology-Heart and Circulatory Physiology website.
} 
Statistics. Data are presented as means \pm SE. Differences among patient groups for discrete clinical variables were evaluated by $\chi^{2}$-test. Coronary hemodynamic and metabolic data were compared in each study condition among groups and for different study conditions in the same group by two-way ANOVA followed by Fisher's exact test. An unpaired $t$-test was used to compare single study conditions between groups when appropriate. $P$ values of $<0.05$ were considered significant.

\section{RESULTS}

\section{Characteristics of the Study Population}

Clinical, functional, and biohumoral data are shown in Table 1. The two groups did not significantly differ in age or sex. History of angina-like chest pain was more frequent in controls, whereas risk factors were similar in the two groups. Body mass index and the ratio of total triglycerides over HDLcholesterol (surrogate measures of insulin resistance and metabolic syndrome) did not differ between the two groups. DCM patients showed reduced LV systolic function and an enlarged LV chamber, frequent left bundle branch block, and higher brain natriuretic peptide (BNP) and $\mathrm{NH}_{2}$-terminal pro-BNP plasma levels. However, DCM patients did not show evidence of advanced heart failure ( 8 of 10 patients in NYHA classes I and II) or extensive sympathetic activation (norepinephrine plasma levels were not significantly different between DCM

Table 1. Clinical, functional, and biohumoral data

\begin{tabular}{|c|c|c|c|}
\hline & Controls & $\begin{array}{c}\text { DCM } \\
\text { Patients }\end{array}$ & $P$ Values \\
\hline \multicolumn{4}{|l|}{ Subject characteristics } \\
\hline$n$ & 6 & 10 & \\
\hline Age, yr & $67 \pm 2$ & $57 \pm 3$ & NS \\
\hline Males & $3(30)$ & $7(70)$ & NS \\
\hline Angina & $5(83)$ & $2(20)$ & $<0.05$ \\
\hline Left branch bundle block & $2(33)$ & $9(90)$ & $<0.05$ \\
\hline LV mass, $\mathrm{g}$ & $164 \pm 11$ & $287 \pm 19$ & $<0.01$ \\
\hline \multicolumn{4}{|l|}{ New York Heart Association class } \\
\hline III & 0 & $2(20)$ & NS \\
\hline \multicolumn{4}{|l|}{ Functional data } \\
\hline LV EF, \% & $58 \pm 1$ & $32 \pm 1$ & $<0.001$ \\
\hline LVEDD, mm & $49 \pm 1$ & $65 \pm 1$ & $<0.001$ \\
\hline \multicolumn{4}{|l|}{ Neurohormonal data } \\
\hline $\mathrm{BNP}, \mathrm{pg} / \mathrm{ml}$ & $21 \pm 7$ & $91 \pm 22$ & $<0.05$ \\
\hline $\mathrm{NH}_{2}$-terminal pro-BNP, pg/ml & $123 \pm 37$ & $593 \pm 130$ & $<0.05$ \\
\hline Norepinephrine, pg/ml & $210 \pm 54$ & $412 \pm 81$ & NS \\
\hline \multicolumn{4}{|l|}{ Risk factors } \\
\hline Body mass index, $\mathrm{kg} / \mathrm{m}^{2}$ & $28 \pm 2$ & $29 \pm 2$ & NS \\
\hline Fasting glycemia, mg/dl & $90 \pm 4$ & $101 \pm 9$ & NS \\
\hline Total triglycerides/HDL-cholesterol & $2.79 \pm 1.73$ & $3.07 \pm 2.71$ & NS \\
\hline HDL/total cholesterol & $0.23 \pm 0.02$ & $0.24 \pm 0.02$ & NS \\
\hline \multicolumn{4}{|l|}{ Treatment } \\
\hline Statins & $3(50)$ & $3(30)$ & NS \\
\hline Antiplatelet & $2(33)$ & $5(50)$ & NS \\
\hline $\mathrm{Ca}^{2+}$ antagonists & $1(17)$ & 0 & NS \\
\hline$\beta$-Blockers (carvedilol) & $3(50)$ & $6(60)$ & NS \\
\hline \multicolumn{4}{|l|}{$\begin{array}{l}\text { Angiotensin-converting enzyme } \\
\text { inhibitors/angiotensin type } 1\end{array}$} \\
\hline receptor antagonists & $3(50)$ & $9(90)$ & NS \\
\hline Antialdosteronics & 0 & $3(30)$ & NS \\
\hline Diuretics & $1(17)$ & $8(80)$ & $<0.05$ \\
\hline Digoxin & 0 & $5(50)$ & $<0.05$ \\
\hline
\end{tabular}

Values are means \pm SE and are numbers of subjects $(n)$ with percentages in parentheses unless otherwise stated. DCM, dilated cardiomyopathy; LV, left ventricular; EF, ejection fraction; LVEDD, LV end-diastolic diameter; BNP, brain natriuretic peptide; NS, not significant.
Table 2. Hemodynamics

\begin{tabular}{lcc}
\hline \hline & Controls & DCM Patients \\
\hline Heart rate, beats/min & & \\
$\quad$ Baseline & $75 \pm 5$ & $71 \pm 4^{\mathrm{a}}$ \\
Pacing & $132 \pm 4^{\mathrm{e}}$ & $124 \pm 4^{\mathrm{a}, \mathrm{e}}$ \\
Recovery & $77 \pm 7$ & $71 \pm 4^{\mathrm{a}}$ \\
Mean aortic pressure, mmHg & & \\
Baseline & $107 \pm 2$ & $89 \pm 3^{\mathrm{b}}$ \\
Pacing & $109 \pm 3^{\mathrm{c}}$ & $91 \pm 4^{\mathrm{b}, \mathrm{c}}$ \\
Recovery & $105 \pm 4$ & $90 \pm 4^{\mathrm{b}}$ \\
Rate-pressure product, & & \\
$\quad$ mmHg $\cdot$ beats $^{\prime} \mathrm{min}^{-1}$ & & \\
Baseline & $8,086 \pm 590$ & $6,320 \pm 413^{\mathrm{b}}$ \\
Pacing & $14,475 \pm 642^{\mathrm{e}}$ & $11,314 \pm 647^{\mathrm{b}, \mathrm{e}}$ \\
Recovery & $8,155 \pm 870$ & $6,438 \pm 440^{\mathrm{b}}$ \\
Left anterior descending coronary artery & & \\
$\quad$ CBF, ml $\cdot$ min $^{-1} \cdot \mathrm{g}^{-1}$ & & \\
Baseline & $1.08 \pm 0.07$ & $0.66 \pm 0.06^{\mathrm{b}}$ \\
Pacing & $1.19 \pm 0.07^{\mathrm{c}}$ & $0.91 \pm 0.07^{\mathrm{b}, \mathrm{d}}$ \\
Recovery & $0.84 \pm 0.04^{\mathrm{f}}$ & $0.64 \pm 0.07^{\mathrm{b}}$ \\
\hline
\end{tabular}

Values are means \pm SE. CBF, coronary blood flow. ${ }^{a} P=$ NS, DCM patients vs. controls; ${ }^{\mathrm{b}} P<0.001$, DCM patients vs. controls; ${ }^{\mathrm{c}} P=\mathrm{NS}$, pacing vs. baseline and recovery; ${ }^{\mathrm{d} P}<0.01$, pacing vs. baseline and recovery; ${ }^{\mathrm{e}} P<$ 0.001 , pacing vs. baseline and recovery; ${ }^{\mathrm{f}} P<0.05$, recovery vs. baseline and pacing.

patients and controls). Use of primary cardioactive drugs was not significantly different between the two groups except for digoxin and diuretics in DCM patients.

\section{Coronary Hemodynamics}

In one patient in the control group, the coronary sinus catheter was displaced into the right atrium; thus, metabolic measurements were not obtained. In two patients of the DCM group, the pacing rate was maintained at 110 beats/min since they did not tolerate higher rates; in one of these two patients and in one other patient, intravenous adenosine was not administered as they asked to shorten the study.

Data on coronary hemodynamics during and after pacing stress are shown in Table 2. While heart rates were not significantly different between controls and DCM patients, coronary mean perfusion pressure, RPP, and CBF in the LAD territory were lower in DCM patients than in controls under all the study conditions. From baseline to pacing, heart rates and RPP significantly increased in both groups and were restored to baseline levels at recovery. CBF significantly increased during pacing only in the DCM group and significantly decreased at recovery in the control group.

During intravenous adenosine infusion, there was a trend for CBF to remain lower in DCM patients than in controls $(2.18 \pm$ 1.30 vs $3.29 \pm 0.89 \mathrm{ml} \cdot \mathrm{min}^{-1} \cdot \mathrm{g}^{-1}, P=0.09$ ), whereas the coronary flow reserve was not significantly different between the two groups $(3.59 \pm 2.53$ vs $3.31 \pm 1.25$, not significant).

\section{Myocardial Metabolism and Energetics}

Baseline arterial concentrations of the major cardiac substrates were not significantly different between the two groups (Table 3) and did not significantly change during the study. DCM patients showed significantly lower FFA uptake and oxidation at all time points and significantly higher glucose uptake than controls at baseline (Fig. 1). During pacing, glucose uptake significantly increased in controls by $106 \%$ but did 
Table 3. Arterial concentration of substrates

\begin{tabular}{lccc}
\hline \hline & Controls & $\begin{array}{c}\text { DCM } \\
\text { Patients }\end{array}$ & $P$ Values \\
\hline FFA & $1.93 \pm 0.21$ & $1.34 \pm 0.18$ & NS \\
Glucose & $5.45 \pm 0.09$ & $5.37 \pm 0.31$ & NS \\
Lactate & $0.51 \pm 0.03$ & $0.61 \pm 0.08$ & NS \\
\hline
\end{tabular}

Values are means \pm SE (in $\mu \mathrm{mol} / \mathrm{ml}$ ). FFA, free fatty acids.

not change in DCM patients, so that it was no longer different between the two groups. The percent net extraction of arterial FFA was unaffected by pacing and was similar between groups (Table 4). On the other hand, glucose and lactate extraction were higher in the DCM group than in the control group. Glucose extraction did not significantly increase during pacing stress in controls but decreased significantly in DCM patients compared with baseline and recovery periods (Table 4).

The tracer-measured myocardial uptake of lactate was not significantly different between controls and DCM patients at baseline and did not show significant changes during stress in both groups (Fig. 2). At recovery, it significantly decreased in controls. Myocardial lactate release was significantly lower in DCM patients than in controls at baseline, but during pacing it significantly increased by $122 \%$ in DCM patients and reached levels similar to controls. Net uptake tended to be higher in DCM patients, but this difference was not statistically significant.

Overall, RPP and $\mathrm{MV}_{2}$ were lower in DCM patients than in controls (Fig. 3). However, the ratio of RPP to $\mathrm{MVO}_{2}$ (an index of myocardial mechanical efficiency, i.e., work performed for a given amount of oxygen consumed) was significantly lower in DCM patients only during stress and at recovery. In fact, during pacing, RPP increased in both groups, but $\mathrm{MV}_{\mathrm{O}_{2}}$ increased only in DCM patients. At recovery, RPP returned to baseline in both groups, but in controls $\mathrm{MVO}_{2}$ declined below baseline levels. The analysis of the percent $\mathrm{MVO}_{2}$ due to oxidation of FFA showed that FFA contributed more to $\mathrm{MV}_{\mathrm{O}_{2}}$ in controls than in DCM patients and that this difference was attenuated during pacing stress (Fig. 4, top). While the contribution of lactate oxidation to $\mathrm{MVO}_{2}$ tended to be greater in DCM patients than in controls, this difference did not reach statistical significance (Fig. 4, bottom).

\section{Correlations Between LV Remodeling and Metabolism, Energetics, and $C B F$}

There was a strong inverse correlation between LV diameter (an index of $\mathrm{LV}$ dysfunction/remodeling) and $\mathrm{CBF}, \mathrm{MV}_{2}$, and FFA uptake in the whole study population under basal conditions (Fig. 5). There was a nonsignificant trend toward a positive correlation with glucose uptake ( $r=0.41$, not significant). Both under resting conditions and during pacing, FFA uptake (but not glucose uptake) was directly related with $\mathrm{MV}_{2}$ (Fig. 6).

\section{DISCUSSION}

This study provides direct evidence for a chronic cardiac metabolic shift under both resting conditions and with pacing stress in DCM patients without advanced heart failure. This change in cardiac metabolic profile was characterized by decreased FFA uptake and oxidation and increased carbohydrate utilization and was associated with reduced cardiac work, $\mathrm{MVO}_{2}$, and myocardial blood flow both at rest and in response to stress. These results suggest the novel view that, while the switch away from FFA oxidation in the failing heart is thought to be compensatory under resting conditions, it may be detrimental during even moderate stress, potentially contributing to the progressive deterioration of myocardial function.
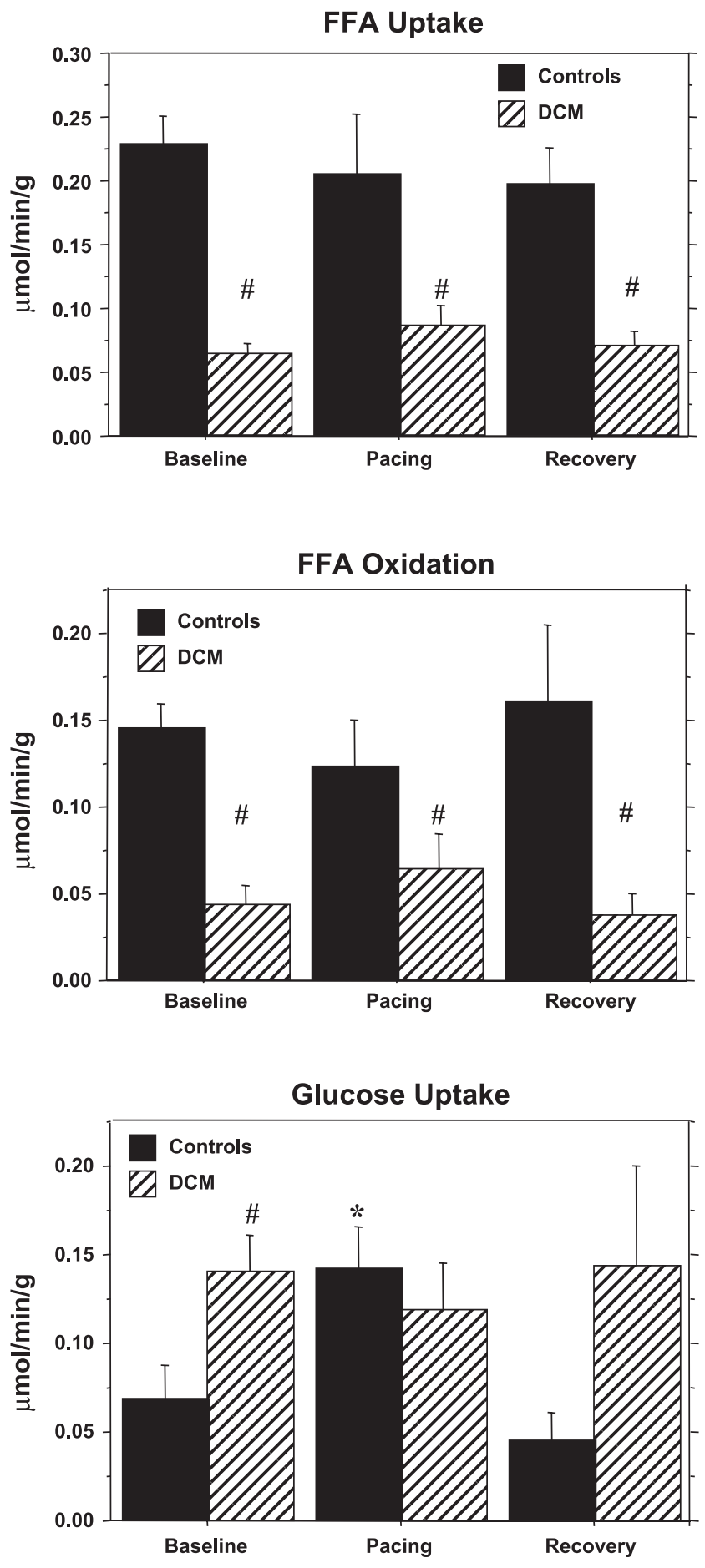

Fig. 1. Cardiac free fatty acid (FFA) uptake (top), FFA oxidation (middle), and glucose uptake (bottom) in controls $(n=5)$ and DCM patients $(n=10)$ at baseline, during atrial pacing, and at recovery. $* P<0.05$, pacing vs. baseline and recovery; $\# P<0.05$, DCM patients vs. controls. 
Table 4. Percent transmyocardial net extraction of arterial FFA, glucose, and lactate

\begin{tabular}{lccc}
\hline \hline & Controls & $\begin{array}{c}\text { DCM } \\
\text { Patients }\end{array}$ & $P$ Value \\
\hline FFA extraction & & & \\
$\quad$ Baseline & $15 \pm 5$ & $18 \pm 10$ & NS \\
Pacing & $12 \pm 5$ & $15 \pm 8$ & NS \\
Recovery & $17 \pm 6$ & $19 \pm 12$ & NS \\
Glucose extraction & $1 \pm 1$ & $4 \pm 2 \dagger$ & $<0.05$ \\
$\quad$ Baseline & $2 \pm 1$ & $2 \pm 2^{* \dagger}$ & NS \\
Pacing & $1 \pm 1$ & $5 \pm 7 \dagger$ & NS \\
Recovery & $18 \pm 14$ & $32 \pm 11 \ddagger$ & \\
Lactate extraction & $17 \pm 12$ & $27 \pm 11 \ddagger$ & NS \\
Baseline & $9 \pm 8$ & $29 \pm 16 \ddagger$ & $<0.05$ \\
Pacing & & & \\
Recovery & &
\end{tabular}

Values are means $\pm \mathrm{SE}$ (in \%). $P$ values are DCM patients versus controls under the given conditions. $* P<0.05$ compared with baseline and recovery; $\dagger P<0.05$, DCM patients vs. control for main effect; $\ddagger P<0.001$, DCM patients vs. controls for main effect.

Previous studies in patients with cardiomyopathy/heart failure have yielded conflicting results. Noninvasive PET studies in nonischemic cardiomyopathy found reduced uptake and oxidation of $\left[{ }^{11} \mathrm{C}\right]$ palmitate $(35)$ and/or increased uptake and utilization of $\left[{ }^{11} \mathrm{C}\right]$ glucose $(7)$, consistent with our direct invasive measurements. However, other PET studies, using FFA and glucose analogs in ischemic and nonischemic patients with advanced heart failure, found opposite results, with increased lipids and decreased carbohydrate uptake $(33,38)$. Paolisso et al. (22) evaluated myocardial energy metabolism in patients with heart failure by direct invasive measurement of transmyocardial substrate gradients and showed increased FFA utilization. However, this study enrolled patients with NYHA class II and III heart failure of ischemic and nonischemic origin and no labeled substrates were used. In the present study, patients were carefully selected to include only those with idiopathic DCM and without advanced heart failure to avoid the potential confounding effects of coronary disease and of systemic metabolic derangement associated with cardiac decompensation. In severe heart failure, elevated adrenergic stimulation may increase $\mathrm{MVO}_{2}$ and levels of FFA, and cardiac insulin resistance may develop (19). As a consequence, both fatty acid and glucose utilization may be altered, and a condition of energy imbalance may ensue, as recently discussed by Neubauer (18).

The resting metabolic pattern that we found in DCM is similar to that observed in the experimental model of pacinginduced cardiomyopathy $(21,25)$ and is consistent with findings in other animal models of progressive cardiac dysfunction and heart failure (11). This shift in myocardial substrate metabolism partially mimics the neonatal metabolic phenotype, with glucose and lactate instead of fatty acid being the primary energy substrate (31). It remains to be determined whether these alterations are a compensatory response of the failing heart that optimizes cardiac energy metabolism and prevents further deterioration of $\mathrm{LV}$ function or rather is a maladaptation that contributes to the progression toward decompensation. Insight on this issue comes from mice with cardiac-specific overexpression of insulin-independent glucose transporter 1, which have increased glucose uptake and less contractile dysfunction and LV dilation in response to chronic pressure overload (15), suggesting that accelerated glucose metabolism prevents hypertension-induced heart failure.

We observed an inverse correlation between cardiac FFA metabolism and the extent of LV remodeling, which was also associated with reduced $\mathrm{MV}_{2}$, myocardial blood flow, and
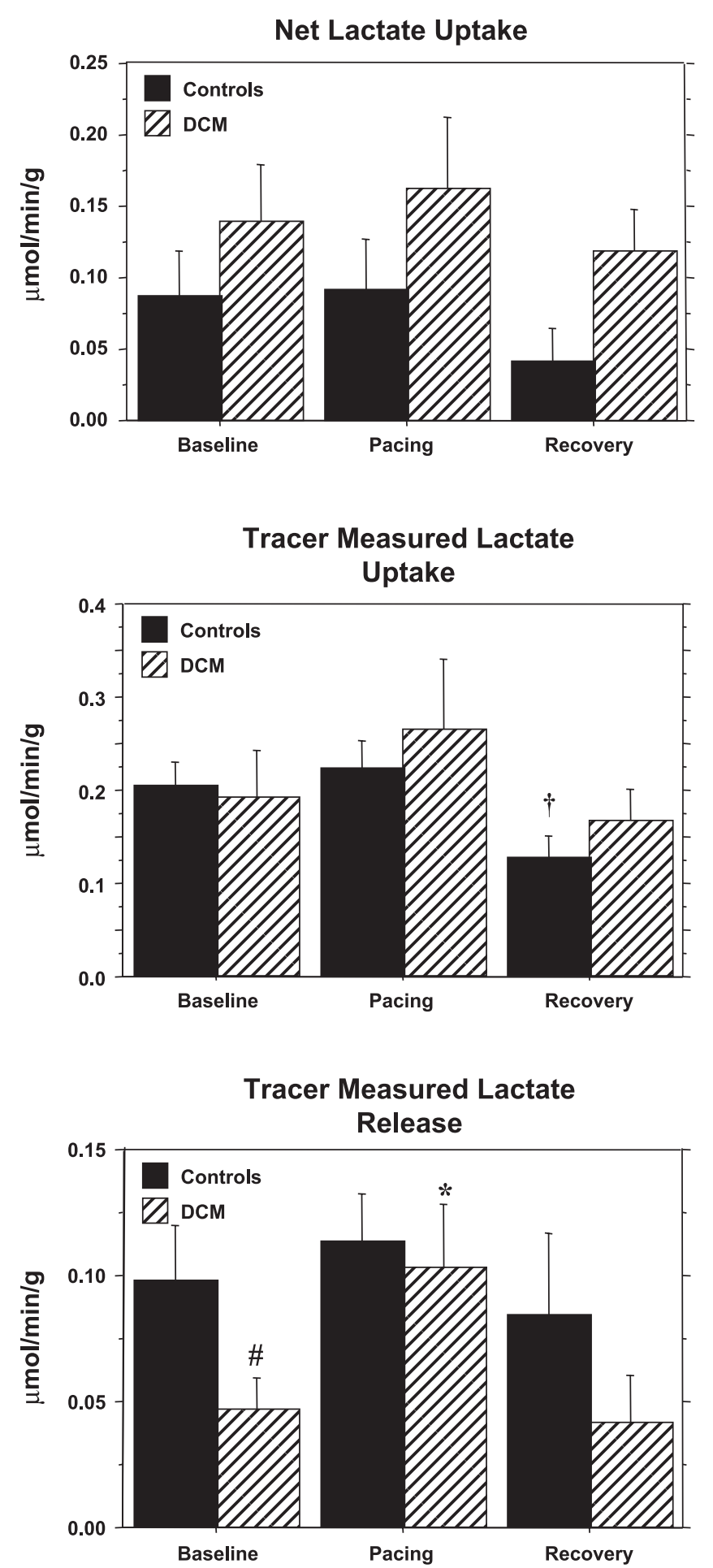

Fig. 2. Cardiac net lactate uptake (top) and tracer-measured lactate uptake (middle) and release (bottom) in controls $(n=5)$ and DCM patients $(n=10)$ at baseline, during atrial pacing, and at recovery. ${ }^{*} P<0.05$, pacing vs. baseline and recovery; $\uparrow P<0.05$, recovery vs. baseline and pacing. $\# P<$ 0.05 , DCM patients vs. controls. 

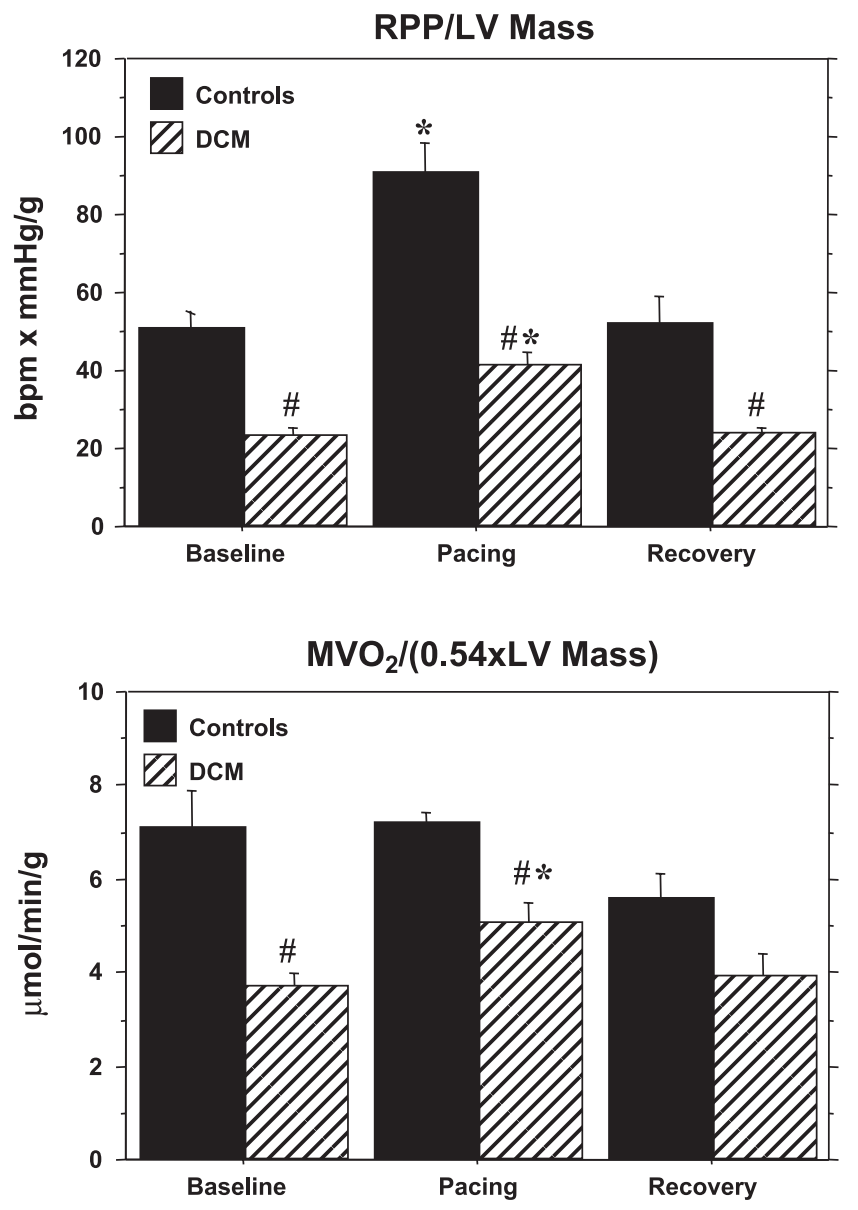

Mechanical Efficiency (RPPx0.54)/ $\mathrm{MVO}_{2}$

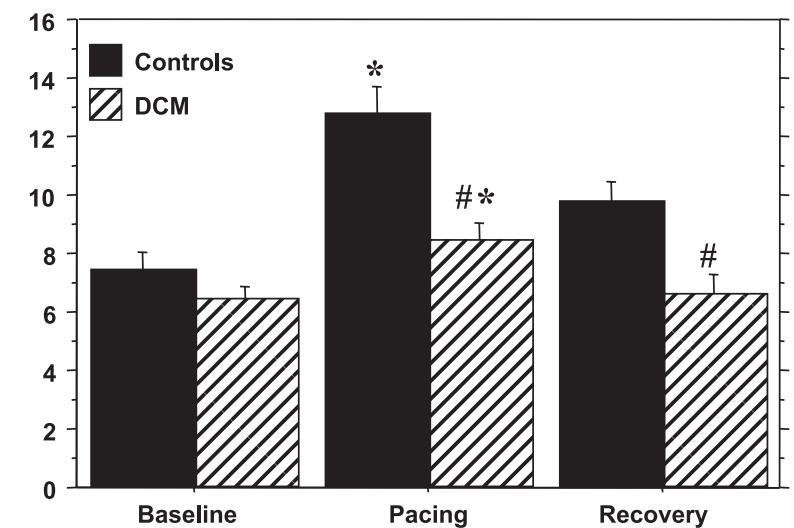

Fig. 3. Rate-pressure product [RPP; in $\mathrm{mmHg} \cdot$ beats $\cdot \min ^{-1}(\mathrm{bpm})$; top], an estimate of cardiac work, myocardial oxygen consumption $\left(\mathrm{MVO}_{2} ;\right.$ middle), and mechanical efficiency, estimated from the ratio between RPP and $\mathrm{MV}_{2}$ (bottom), in controls $(n=5)$ and DCM patients $(n=10)$ at baseline, during atrial pacing, and at recovery. All values were corrected for left ventricular (LV) myocardial mass. $* P<0.05$, pacing vs. baseline and recovery; $\# P<$ 0.05 , DCM patients vs. controls.

cardiac work. A primary depression of myocardial function, as can be expected in DCM, could cause reduced energy requirements and $\mathrm{MV}_{2}$ and consequently reduced blood flow with downregulation of FFA metabolism and a possible increase in carbohydrate utilization. A reduction of myocardial oxygen availability due to impaired myocardial perfusion and coronary microvascular dysfunction $(16,17)$ and impaired oxygen utilization consequent to mithocondrial dysfunction (28) have been also described in DCM. These mechanisms reduce energy transduction and further impair contractility and could, by themselves, stimulate the myocardial metabolic shift from fat oxidation to preferential utilization of carbohydrates. On the other hand, a primary metabolic abnormality could exist, with lower activity of the $\beta$-oxidation pathway (27), lowering $\mathrm{MV}_{2}$ and causing metabolic downregulation of coronary flow, but also energy depletion and reduced contractile function.

\section{Myocardial Metabolic Response to Stress in DCM}

The myocardial metabolic response to stress in DCM patients had not previously been investigated. It is well established that in normal hearts, a high rate pacing induces a rapid increase in glucose and lactate uptake coupled with a relative decline in FFA uptake $(1,3,4,9)$. Clinical and experimental studies have suggested that this response is advantageous, since it increases myocardial mechanical efficiency as carbohydrates are a more efficient substrate than lipids and provides more energy for the generation of contractile power for any given $\mathrm{MV}_{\mathrm{O}_{2}}(20,29,31)$. The response to pacing stress in
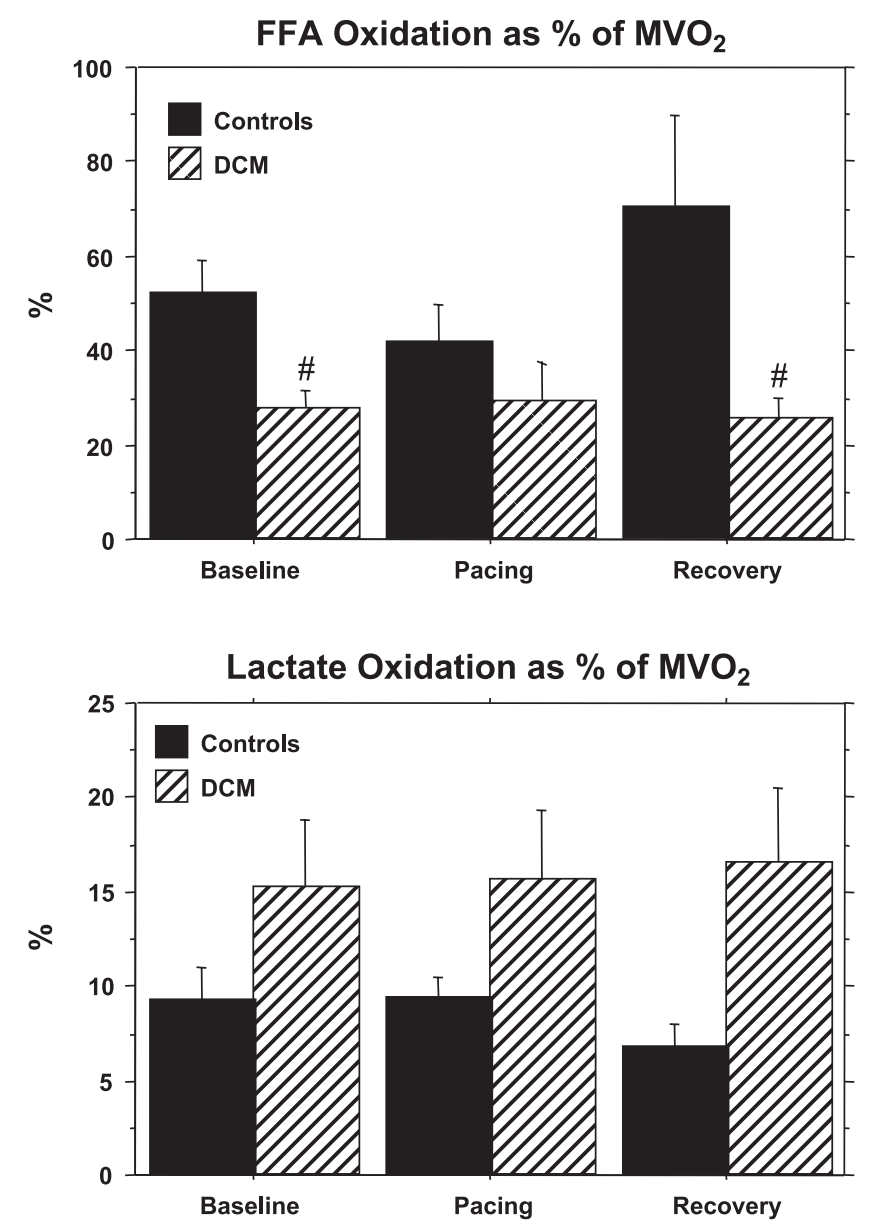

Fig. 4. Percent contribution of FFA oxidation (top) or lactate oxidation (bottom) to $\mathrm{MVO}_{2}$ in controls $(n=5)$ and DCM patients $(n=10)$ at baseline, during atrial pacing, and at recovery. $\# P<0.05$, DCM patients vs. controls. 

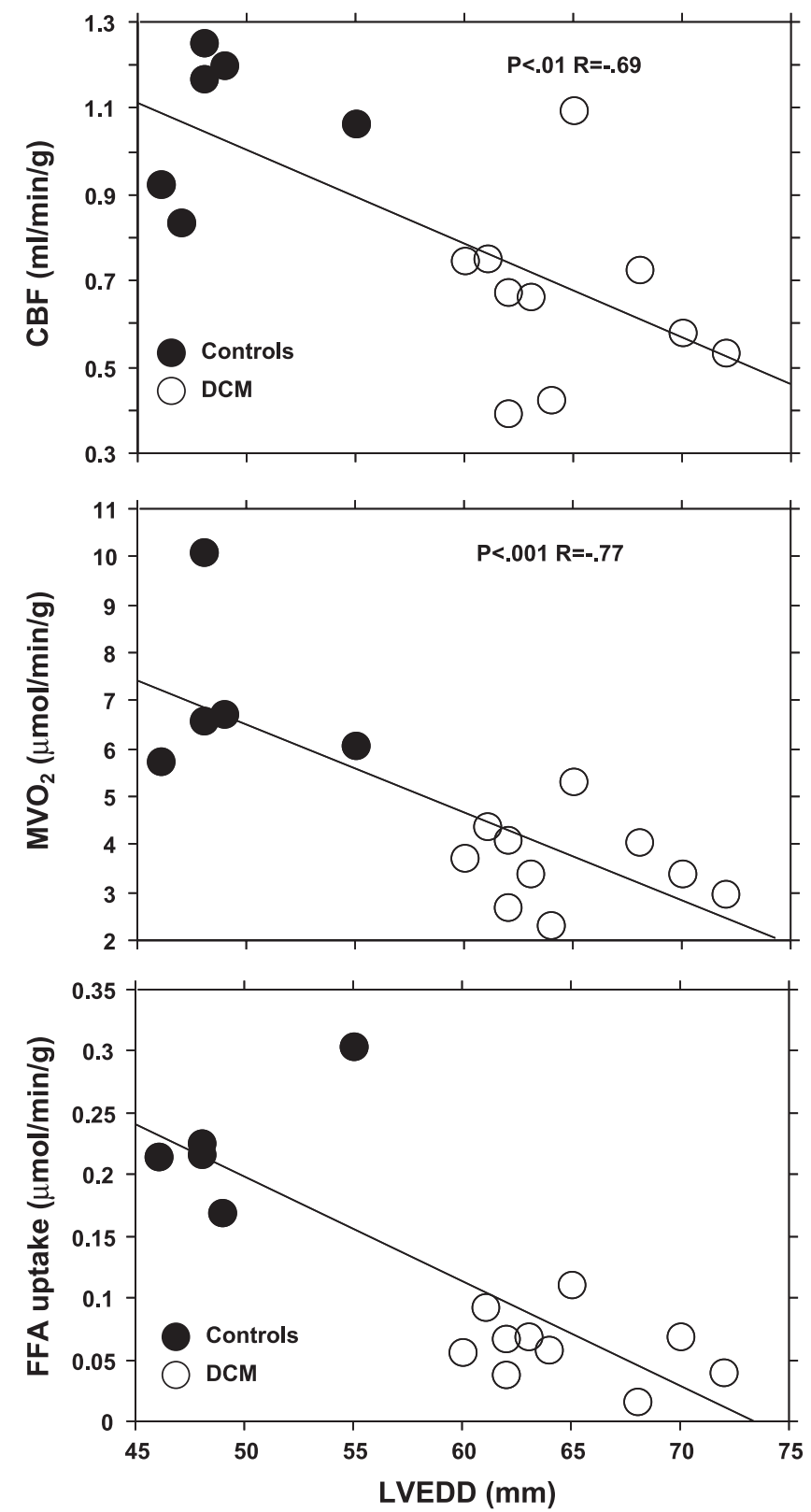

Fig. 5. Correlations between LV end-diastolic diameter (LVEDD) and resting coronary blood flow (CBF; top), $\mathrm{MV்}_{2}$ (middle), and myocardial FFA uptake (bottom) in controls and DCM patients.

DCM patients was very different from the control group: glucose uptake, which at baseline was already elevated in DCM patients to levels similar to those reached in controls during stress, did not further increase. In contrast, FFA utilization tended to increase and the relative contribution of lipid oxidation to $\mathrm{MV}_{2}$, which was clearly lower in DCM patients than in controls under resting conditions, became similar between the two groups during stress. Compared with controls, there was a lower increase in myocardial mechanical efficiency during pacing in DCM patients. Taken together, these findings strongly indicate that there is a more limited cardiac metabolic reserve and flexibility in DCM. One of the possible mechanisms explaining the metabolic rigidity of the failing heart is the paradoxical downregulation of key enzymes of the carbo- hydrate oxidative pathway, despite the higher glucose oxidation, which we have previously described in dogs (14). As a consequence, the cardiomyopathic heart must face even moderate increases in cardiac work by oxidizing less efficient substrates, such as FFA, which require higher oxygen consumption and blood flow.

This abnormal metabolic behaviour, together with impaired mitochondrial function (28) and limited myocardial flow and oxygen availability, possibly due to coronary microvascular dysfunction $(16,17)$, could contribute to an ischemic-like condition $(6,36)$, enhanced oxidative stress, and energy depletion in the cardiomyopathic heart.

\section{Study Limitations}

The small number of both DCM and control patients, due to the strict selection criteria and the complexity of the protocol, limits the statistical power. A second limitation is the lack of a completely normal control population. Control patients had a history of angina-like chest pain and/or stress testing suggestive for ischemia. However, neither group of patients had the typical clinical and ECG pattern of syndrome X nor developed
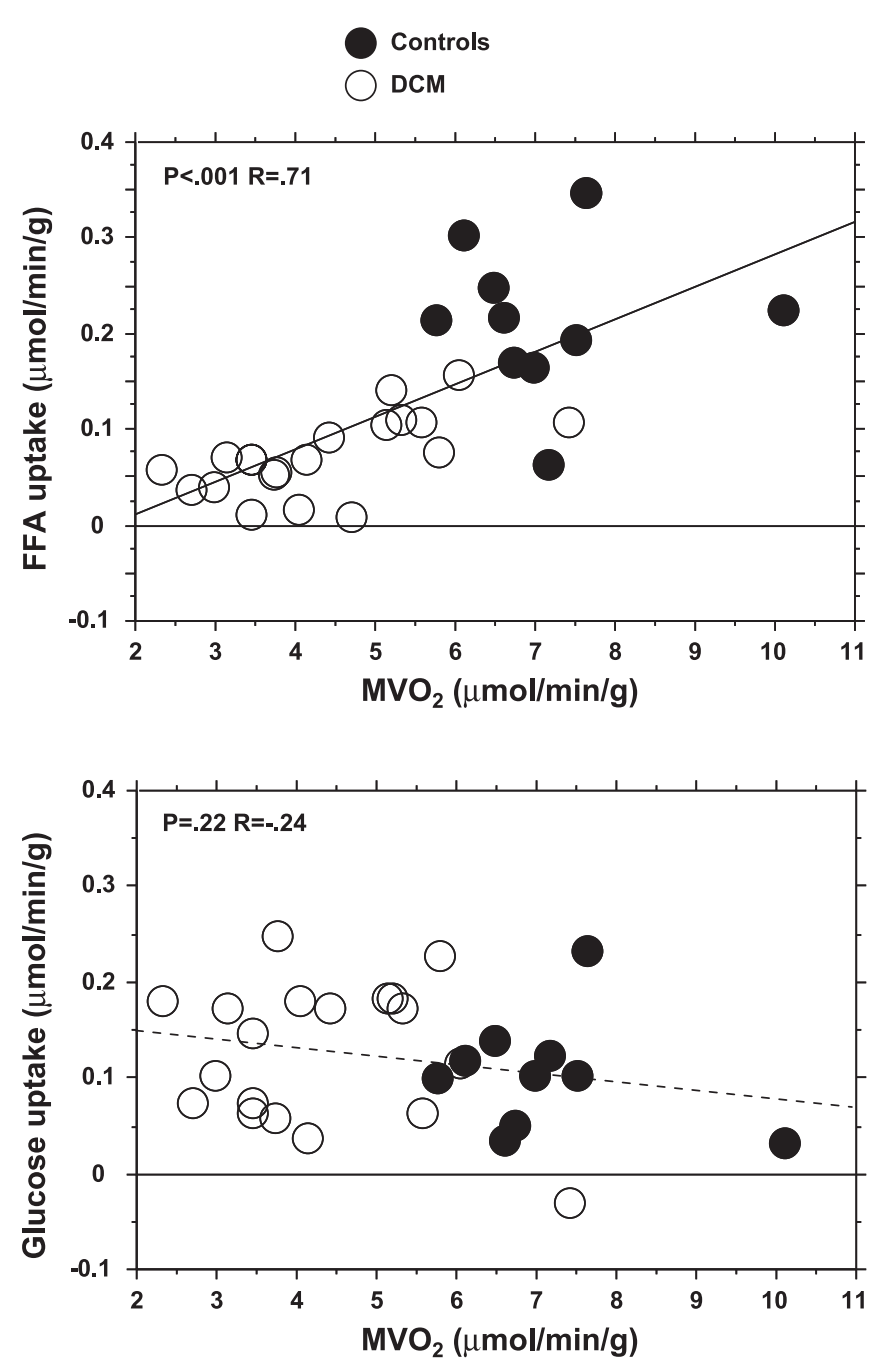

Fig. 6. Correlations between $\mathrm{MVO}_{2}$ and myocardial FFA uptake (top) and glucose uptake (bottom) measured at rest and during pacing in controls and DCM patients. 
chest pain or significant S-T segment depression during pacing stress. Since coronary catheterization procedures have an intrinsic risk to life, it is unethical to study a truly normal population.

Glucose oxidation was not measured because of the significant additional adsorbed radiation dose to the patient. It is important to know the effects of DCM and acute stress on glucose uptake and oxidation to $\mathrm{CO}_{2}$ and release of lactate, which can only be assessed using $\left[{ }^{14} \mathrm{C}\right]$ glucose. While the present study is the first to assess myocardial lactate kinetics in DCM patients using $\left[{ }^{13} \mathrm{C}\right]$ lactate tracers, these experiments would be greatly strengthened by dual-isotopic studies using $\left[{ }^{14} \mathrm{C}\right]$ glucose/ $\left[{ }^{13} \mathrm{C}\right]$ lactate tracers, as previously described $(9$, 39). Another limitation in the metabolic measurements is the inability to measure the oxidation of intracardiac substrate stores (e.g., glycogen and triglycerides), which likely played an important role in supporting the increase in $\mathrm{MVO}_{2}$ in response to pacing in the DCM group (Fig. 3).

Diabetes was an exclusion criterion for enrolment of both DCM and control patients; however, it cannot be excluded that the two patient populations differ in insulin resistance, and that this could have influenced the metabolic response to stress. Oral glucose tolerance test was not performed, however, BMI and the triglycerides/HDL was similar between the two groups, suggesting that whole body metabolic abnormalities were similar.

According to the study protocol, pacing moderately increased heart rate to allow tolerability in DCM patients. This choice could have caused a relatively lower increase in cardiac workload in normal hearts than in cardiomyopathic hearts where the effects of heart rate on energy expenditure are added to those of enhanced wall stress. Due to the complexity of the protocol we could not measure ventricular volumes to have a better estimate of actual workload than that provided by RPP values. The somewhat artificial conditions of studying these patients in the catheterization laboratory and the use of heparin likely resulted in elevated FFA in both groups. Accordingly, baseline metabolic data should be extended with caution to what one would see in the unheparized resting state. It would be best to use a more physiological stimulus to increase $\mathrm{MVO}_{2}$, such as exercise or high dose dobutamine infusion, however, these stresses are not feasible in instrumented patients with DCM prone to arrhythmias.

\section{Conclusions}

The present findings demonstrate that DCM patients have a shift in cardiac metabolism away from FFA oxidation both at rest and during pacing stress, which is associated with enlargement of the $\mathrm{LV}$ and reduced cardiac work, $\mathrm{MVO}_{2}$, and myocardial blood flow. In addition, these patients show a failure to further increase glucose uptake and possibly oxidative glycolysis in response to pacing stress. Our results suggest the novel view that, while the switch away from FFA oxidation in DCM hearts appears to be compensatory under resting conditions, it may be detrimental during even moderate stress, potentially contributing to progressive deterioration of myocardial function. These findings will better orient therapeutic strategies aimed at modulating mitochondrial substrate oxidation to reduce symptoms and improve cardiac performance in DCM patients $(2,13)$.

\section{GRANTS}

This work was supported by intramural funds of the Italian National Council for Research. F. A. Recchia is an Established Investigator of the American Heart Association.

\section{REFERENCES}

1. Bagger JP, Thomassen A, Nielsen TT. Cardiac energy metabolism in patients with chest pain and normal coronary angiograms. Am J Cardiol 85: 315-320, 2000.

2. Belardinelli R, Purcaro A. Effects of trimetazidine on the contractile response of chronically dysfunctional myocardium to low-dose dobutamine in ischaemic cardiomyopathy. Eur Heart J 22: 2164-2170, 2002.

3. Camici P, Marraccini P, Lorenzoni R, Buzzigoli G, Pecori N, Perissinotto A, Ferrannini E, L'Abbate A, Marzilli M. Coronary hemodynamics and myocardial metabolism in patients with syndrome $\mathrm{X}$ : response to pacing stress. J Am Coll Cardiol 17: 1461-1470, 1991.

4. Camici P, Marraccini P, Marzilli M, Lorenzoni R, Buzzigoli G, Puntoni R, Boni C, Bellina CR, Klassen GA, L'Abbate A. Coronary hemodynamics and myocardial metabolism during and after pacing stress in normal humans. Am J Physiol Endocrinol Metab 257: E309-E317, 1989.

5. Cerqueira MD, Weissman NJ, Dilsizian V, Jacobs AK, Kaul S, Laskey WK, Pennell DJ, Rumberger JA, Ryan T, Verani MS. Standardized myocardial segmentation and nomenclature for tomographic imaging of the heart. A statement for healthcare professionals from the Cardiac Imaging Committee of the Council on Clinical Cardiology of the American Heart Association. Circulation 105: 539-542, 2002.

6. Chen JW, Ting CT, Chen YH, Wu TC, Hsu NW, Lin SJ, Chang MS. Differential coronary microvascular function in patients with left ventricular dysfunction of unknown cause: implication for possible mechanism of myocardial ischemia in early stage of cardiomyopathy. Int J Cardiol 69: 251-261, 1999.

7. Davila-RomanVG, Vedala G, Herrero P, de las Fuentes L, Rogers JG, Kelly DP, Gropler RJ. Altered myocardial fatty acid and glucose metabolism in idiopathic dilated cardiomyopathy. J Am Coll Cardiol 40: 271-277, 2002.

8. Gertz EW, Wisneski JA, Neese R, Bristow JD, Searle GL, Hanlon JT. Myocardial lactate metabolism: evidence of lactate release during net chemical extraction in man. Circulation 63: 1273-1279, 1981.

9. Gertz EW, Wisneski JA, Stanley WC, Neese RA. Myocardial substrate utilization during exercise in humans. Dual carbon-labeled carbohydrate isotope experiments. J Clin Invest 82: 2017-2025, 1988.

10. Hall JL, Stanley WC, Lopaschuk GD, Wisneski JA, Pizzurro RD, Hamilton CD, McCormack JG. Impaired pyruvate oxydation but normal glucose uptake in diabetic pig heart during dobutamine-induced work. Am J Physiol Heart Circ Physiol 271: H2320-H2329, 1996.

11. Heather LC, Cole MA, Lygate CA, Evans RD, Stuckey DJ, Murray AJ, Neubauer S, Clarke K. Fatty acid transporter levels and palmitate oxidation rate correlate with ejection fraction in the infarcted rat heart. Cardiovasc Res 72: 430-437, 2006.

12. Lang RM, Bierig M, Devereux RB, Flachskampf FA, Foster E, Pellikka PA, Picard MH, Roman MJ, Seward J, Shanewise J, Solomon S, Spencer KT, St John Sutton M, Stewart W; American Society of Echocardiography's Nomenclature and Standards Committee; Task Force on Chamber Quantification; American College of Cardiology Echocardiography Committee; American Heart Association; European Association of Echocardiography, European Society of Cardiology. Recommendations for chamber quantification. Eur $J$ Echocardiogr 7: 79-108, 2006.

13. Lee L, Campbell R, Scheuermann-Freestone M, Taylor R, Gunaruwan P, Williams L, Ashrafian H, Horowitz J, Fraser AG, Clarke K, Frenneaux M. Metabolic modulation with perhexiline in chronic heart failure: a randomized, controlled trial of short-term use of a novel treatment. Circulation 112: 3280-3288, 2005.

14. Lei B, Lionetti V, Young ME, Chandler MP, D’ Agostino C, Kang E, Altarejos M, Matsuo K, Hintze TH, Stanley WC, Recchia FA. Paradoxical downregulation of the glucose oxidation pathway despite enhanced flux in severe heart failure. J Mol Cell Cardiol 36: 567-576, 2004.

15. Liao R, Jain M, Cui L, D'Agostino J, Aiello F, Luptak I, Ngoy S, Mortensen RM, Tian R. Cardiac-specific overexpression of GLUT1 prevents the development of heart failure attributable to pressure overload in mice. Circulation 106: 2125-2131, 2002. 
16. Neglia D, Nichelassi C, Trovieri MG, Sambuceti G, Giorgetti A, Pratali L, Gallopin M, Salvadori P, Sorace O, Carpeggiani C, Poddighe R, L'Abbate A, Parodi O. Prognostic role of myocardial blood flow impairment in idiopathic left ventricular dysfunction. Circulation 105: 186-193, 2002.

17. Neglia D, Parodi O, Gallopin M, Sambuceti G, Giorgetti A, Pratali L, Salvadori P, Michelassi C, Lunardi M, Pelosi G, L'Abbate A. Myocardial blood flow response to pacing tachycardia and to dipyridamole infusion in patients with dilated cardiomyopathy without overt heart failure. A quantitative assessment by positron emission tomography. Circulation 92: 796-804, 1995.

18. Neubauer S. The failing heart-an engine out of fuel. N Engl J Med 356: 1140-51, 2007.

19. Nikolaidis LA, Sturzu A, Stolarski C, Elahi D, Shen YT, Shannon RP. The development of myocardial insulin resistance in conscious dogs with advanced dilated cardiomyopathy. Cardiovasc Res 61: 297-306, 2004.

20. Opie LH. The Heart: Physiology and Metabolism. New York: Raven, 1991, p. 208-276.

21. Osorio JC, Stanley WC, Linke A, Castellari M, Diep QN, Panchal AR, Hintze TH, Lopaschuk GD, Recchia FA. Impaired myocardial fatty acid oxidation and reduced protein expression of retinoid X receptor-alpha in pacing-induced heart failure. Circulation 106: 606-612, 2002.

22. Paolisso G, Gambardella A, Galzerano D, D'Amore A, Rubino P, Verza M, Teasuro P, Varricchio M, D'Onofrio F. Total-body and myocardial substrate oxidation in congestive failure. Metabolism 43: 174-179, 1994.

23. Parker JO, Chiong MA, West RO, Case RB. Sequential alterations in myocardial lactate metabolism, S-T segments, and left ventricular function during angina induced by atrial pacing. Circulation 40: 113-131, 1969.

24. Parker JO, West RO, Case RB, Chiong MA. Temporal relationships of myocardial lactate metabolism, left ventricular function, and S-T segment depression during angina precipitate by exercise. Circulation 40: 97-111, 1969.

25. Recchia FA, McConnell PI, Bernstein RD, Vogel TR, Xu X, Hintze TH. Reduced nitric oxide production and altered myocardial metabolism during the decompensation of pacing-induced heart failure in the conscious dog. Circ Res 83: 969-979, 1998.

26. Recchia FA, Osorio JC, Chandler Xu X, Panchal RA, Lopaschuk GD, Hintze TH, Stanley WC. Reduced synthesis of NO causes marked alterations in myocardial substrate metabolism in conscious dogs. Am J Physiol Endocrinol Metab 282: E197-E206, 2002.

27. Sack MN, Rader TA, Park S, Bastin J, McCune SA, Kelly DP. Fatty acid oxidation enzyme gene expression is downregulated in the failing heart. Circulation 94: 2837-2842, 1996.
28. Schulze K, Dörner A, Schultheiss HP. Mitochondrial function in heart failure. Heart Failure Rev 4: 229-244, 1999.

29. Simonsen S, Kjekshus JK. The effect of free fatty acids on myocardial oxygen consumption during atrial pacing and catecholamine infusion in man. Circulation 58: 484-491, 1978.

30. Smith CS, Bottomley PA, Schulman SP, Gerstenblith G, Weiss RG. Altered creatine kinase adenosine triphosphate kinetics in failing hypertrophied human myocardium. Circulation 114: 1151-1158, 2006.

31. Stanley WC, Recchia FA, Lopaschuk GD. Myocardial substrate metabolism in the normal and failing heart. Physiol Rev 85: 1093-1129, 2005.

32. Stanley WC. Partial fatty acid oxidation inhibitors for stable angina. Expert Opin Investig Drugs 11: 615-629, 2002.

33. Taylor M, Wallhaus TR, DeGrado TR, Russell DC, Stanko P, Nickles RJ, Stone CK. An evaluation of myocardial fatty acid and glucose uptake using PET with $\left[{ }^{18} \mathrm{~F}\right]$ fluoro-6-thia-heptadecanoic acid and $\left[{ }^{18} \mathrm{~F}\right] \mathrm{FDG}$ in patients with congestive heart failure. J Nucl Med 42: 55-62, 2001.

34. Tuunanen H, Engblom E, Naum A, Nagren K, Hesse B, Airaksinen KE, Nuutila P, Iozzo P, Ukkonen H, Opie LH, Knuuti J. Free fatty acid depletion acutely decreases cardiac work and efficiency in cardiomyopathic heart failure. Circulation 114: 2130-2137, 2006.

35. Tuunanen H, Engblom E, Naum A, Scheinin M, Nagren K, Airaksinen J, Nuutila P, Iozzo P, Ukkonen H, Knuuti J. Decreased myocardial free fatty acid uptake in patients with idiopathic dilated cardiomyopathy: evidence of relationship with insulin resistance and left ventricular dysfunction. J Card Fail 12: 644-652, 2006.

36. van den Heuvel AF, van Veldhuisen DJ, van der Wall EE, Blanksma PK, Siebelink HM, Vaalburg WM, van Gilst WH, Crijns HJ. Regional myocardial blood flow reserve impairment and metabolic changes suggesting myocardial ischemia in patients with idiopathic dilated cardiomyopathy. J Am Coll Cardiol 35: 19-28, 2000.

37. Vitale C, Wajngaten M, Sposato B, Gebara O, Rossigni P, Fini M, Volterrani M, Rosano GM. Trimetazidine improves left ventricular function and quality of life in elderly patients with coronary artery disease. Eur Heart J 25: 1814-1821, 2004.

38. Wallhaus TR, Taylor M, DeGrado Russell DC, Stanko P, Nickles RJ, Stone CK. Myocardial free fatty acid and glucose use after carvedilol treatment in patients with congestive heart failure. Circulation 103: 2441-2446, 2001.

39. Wisneski JA, Gertz EW, Neese RA, Gruenke LD, Craig JC. Dual carbon-labeled isotope experiments using D-[6-14C] glucose and L-[1,2,313C3] lactate: a new approach for investigating human myocardial metabolism during ischemia. J Am Coll Cardiol 5: 1138-1146, 1985. 